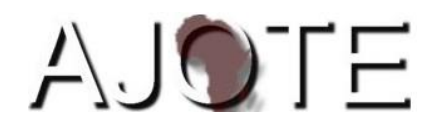

African Journal of Teacher Education

ISSN 1916-7822. A Journal of Spread Corporation

Volume $10 \quad$ No.1 $2021 \quad$ Pages 346-364

\title{
Online Learning Amidst COVID-19 Emergency: A Case of the University of Malawi's School of Education
}

\author{
Bob Maseko, Foster Gondwe, Symon Winiko, \& Symon Chiziwa \\ Chancellor College, School of Education \\ University of Malawi.
}

ABSTRACT

This paper explores faculty members' concerns and level of preparedness for open and distance learning (ODL) at the University of Malawi's School of Education during the recent Covid-19 pandemic within a context that considers ODL as a means of mitigating the impact of the pandemic on teaching and learning. Data were gathered through semi-structured interviews with four experienced academic leaders within the school of education. The Concerns Based Adoption Model (CBAM), particularly stages of concerns, served as a framework to understand the faculty's concerns about the implementation of ODL initiatives. Inductive and deductive analysis approaches were used to analyse the interview transcripts to identify emerging themes. Deductive analysis revealed that faculty members expressed several concerns such as awareness, informational, as well as consequences concerns as they talked about their feelings and attitudes towards the implementation of ODL. Inductive analysis on the other hand revealed that faculty members' perceptions such as minimal preparation, negative orientations, and lack of policy awareness hamper the implementation of ODL. These findings underscore the importance of members' orientation change to ensure effective implementation of ODL in contexts like the institution under study. We discuss these and propose that professional development could help members develop positive attitudes towards ODL.

Keywords: concerns; concern-based adoption model; open distance learning, COVID-19 


\section{INTRODUCTION}

The COVID-19 outbreak around the world has changed the education landscape in different ways; one of which is the renewed efforts by most institutions to accelerate the implementation of Open and Distance Learning (ODL). Considering the contagious nature of the disease, most governments are still implementing drastic 'social distancing' measures, including the closure of schools. At the same time, COVID-19's impact on education is attracting the interest of researchers, mostly seeking to generate evidence that can inform education delivery in times of similar emergencies now and in the future. In this paper, we join research efforts on the theme of educational institutions and staff preparedness to implement ODL during an emergency such as COVID-19. We analyse the concerns of the University of Malawi's School of Education faculty members about the implementation of ODL.

The implementation of ODL has been slow (Mtingwi \& Belle, 2012) partly because both students and teachers have a negative attitude towards ODL (Smidt et al., 2014). For instance, research evidence suggests that most students in Malawi question the authenticity of ODL (Mkandawire \& Kaphesi, 2017), and many higher education institutions lack the financial capacity to effectively roll out ODL (Tembo, 2019). For instance, internet-based ODL requires access not only to reliable and fast internet services but also the devices, such as laptops, to enable both students and teachers to have access to ODL materials. Unfortunately, most people in Malawi do not have reliable internet services and electronic gadgets to use to access these platforms (Zozie \& Chawinga, 2018).

Considering the above background, implementing ODL in Malawi seems like an impossibility. However, the closure of educational institutions due to COVID-19 has attracted government policy interest to fast-track the implementation of ODL initiatives. This is evidenced by the governments' commitment in partnering with internet service providers to offer affordable services to education institutions (Mkandawire, 2020). Building upon this renewed interest, especially in higher education institutions, this study focused on faculty's readiness to adopt ODL as a form of education innovation. Bourn (2016) shows that successful implementation of an education innovation should ensure an understanding of the concerns of the teachers and supporting them throughout the process. The literature on innovation implementation (e.g. Bourn, 
2016) shows that teachers as change agents do not implement education innovations uniformly as these 'change agents' go through the various stages of concerns while implementing the innovations. The purpose of this study is to investigate the University of Malawi faculty's concerns on the implementation of ODL in Malawi.

\section{LITERATURE REVIEW}

\section{The Concept of Open and Distance Learning (ODL)}

There are diverse perspectives, attributed to changes in technology, concerning the notion of distance education, with some focusing on the medium of teaching and learning, while others focus on the nature of the actual teaching and learning process (cf Greenberg, 1998; Teaster \& Blieszner, 1999). Furthermore, there is inconsistent use of terms in the literature related to this subject (Moore et al., 2011). Terms such as e-learning (usage of electronics in the teaching and learning process), online learning (students interact with their teachers using connected computers) or distance education (teacher and learner are physically separated from one another) are synonymously used. ODL is mostly described as a kind of teaching methodology where learners and teachers are separated either by space or time for a significant portion of their learning (Commonwealth of Learning, 2002). While the students and the teachers remain separated, they either communicate via postal mails, or online facilities (Zozie \& Chawinga, 2018). We focused on ODL that relies on digital technologies such as Moodle. The aim was to understand the faculty's concerns regarding the use of such facilities amidst COVID-19.

\section{Faculty Role in Implementation of ODL}

Since this study focuses on teacher education faculty, we highlight the professional roles of teacher educators to illustrate why it is necessary to consider their concerns as teacher education institutions transition to ODL in the context of COVID-19. According to the literature, teacher educators perform roles such as teacher of teacher, researcher, curriculum developer etc. (Lunenberg, et al., 2014). Hence teacher educators should possess unique knowledge: pedagogy of teacher education and understanding of policy that guides teacher education in specific contexts (Goodwin \& Kosnik, 2013). The literature also shows that teacher educators face challenges as they transition from one professional phase or space to another. For example, as they transition 
from school teaching to higher education, novice teacher educators have to cope with the demands of a research culture in higher education (Ping et al., 2018). Yet, induction to support such beginning teacher educators is very scarce in many institutions partly due to the lack of formal curriculum (Lunenberg et al., 2014; Ping et al., 2018). With limited professional development opportunities, teacher educators rely on learning at the workplace.

The above reflection suggests that research on teacher educators' concerns and challenges in different professional phases has been useful for determining their professional development content and activities. Recently, COVID-19 has presented a mix of new experiences for the profession of teacher educators. On one hand, teacher educators have started "exploring and experimenting with new ways to teach and learn using innovative technologies" (Ferdig \& Pytash, 2021) Furthermore, the already known education problems such as inequitable access to education have become known in greater detail because of the pandemic (Ferdig \& Pytash, 2021). On the other hand, the pandemic has presented new demands on the work of teacher educators, including changes in approaching teaching practicum and developing a teacher education curriculum that responds to the emerging needs of future teachers (Mutton, 2020). As teacher educators around the world experience this uncertain transitional phase due to COVID-19, it is necessary to consider their needs, challenges and concerns as the basis for their continuing professional development.

Meanwhile, international research on how the pandemic is impacting the work of teacher educators (e.g. Ferdig \& Pytash, 2021; Mutton, 2020) has offered valuable insights into potential ways of supporting teacher educators. For example, Ferdig and Pytash (2021) have suggested the need to prepare student teachers for online learning experiences as one of the lessons that teacher educators should have learnt following the pandemic. However, as teacher educators long for the time when things will 'get back to normal (Ferdig \& Pytash, 2021), further research is required to continue drawing lessons that might generate sustainable ways of supporting teacher educators. Therefore, in this paper, we consider teacher education faculty concerns in Malawi, where there has been limited research on teacher educators' experiences' with the pandemic. We expect that the findings reported in this study will benefit the international literature for further comparisons with similar contexts. 


\section{THEORETICAL FRAMEWORK}

To understand faculty concerns on ODL, we followed the Concerns Based Adoption Model (CBAM) that tracks the concerns of implementers of change (Anderson, 1997). Hall and Hord (2015) describe CBAM as an important tool that defines and explain concerns of implementers of educational innovations. The CBAM allows researchers to probe the implementers of the innovation with three diagnostic keys: (1) Stages of Concern (SoC), (2) Levels of Use (LoU), (3) Innovation Configuration (IC). For this paper, we employed the SoC key which refers to how implementers view an innovation or idea to be implemented. The seven elements of the SoC components cluster into three: self, tasks and impact. While subjecting participants through items on this, it is believed that they reflect on the "self", "task" as well as the "impact" of the innovation being implemented. The focus is on the implementers' beliefs, attitudes or perceptions about innovation. This level has seven stages (briefly described in Table 1). It is assumed that the implementers would undergo these seven SoC as they implement an innovation.

\section{Table 1: The seven stages of concerns}

\section{No. stage Description of Concern}

1 Awareness This is where the teacher has some basic awareness of the key elements of the innovation being implemented. In this case, the issue is to what extent are the teacher educators aware of the open and distance learning being implemented

2 Informational At this stage, the teachers' focus on learning more about the innovation so that he has an in-depth understanding of the innovation i.e. open distance learning platform

3 Personal Here the teacher focuses on the individual. for instance, the role he is going to play, the personal demands and the challenges experienced

4 Management Here the teachers' focus is on the pedagogical efficiency of the innovation, organization and the best use of the various resources at hand.

5 Consequences At this stage, the teachers' focus is on the impact of the innovation. 

6 Collaboration Coordination and cooperation with others with the object of improving practice

7 Refocusing Exploration of more effective alternatives Personal initiative, creativity

Recently, several tools have been developed to capture the SoC. However, the focus seems to be on the quantitative aspects (see Kang \& Everhart, 2014; Trapani, 2019). While quantitative approaches to measuring the $\mathrm{SoC}$ provide useful insights, it is mostly prescriptive hence our resolve to apply the key qualitatively to have an in-depth understanding of the participants' beliefs about ODL. Concerns refer to "the composite representation of the feelings, preoccupation, thoughts, and consideration given to a particular issue or ask or innovation"(Hall \& Hord, 2015, p. 152). The deployment of distance learning at the University of Malawi is a new thing hence it was imperative to understand the implementers' feelings, thoughts and preoccupations as this will provide useful insights to those managing the implementation process.

In this paper, we specifically consider faculty concerns on ODL that has gained prominence in research and policy following the recent outbreak of COVID-19. The following questions guided the study:

1. What are the faculty's concerns toward the implementation of ODL in the university?

2. What are the faculty perceptions of the school of education's readiness/preparedness to implement ODL?

\section{METHODOLOGY}

\section{Research Design and Study Participants}

To achieve the aim of the study, we took the qualitative research approach within the interpretivists paradigm (Creswell, 2012). We specifically used the case study design (Hancock, 2006) to allow for an exploration and analysis of participants concerns about ODL.

\section{Study Context and Participants}

We worked with seven participants from Chancellor Colleges' school of education. These participants were purposely sampled (Merriam \& Merriam, 2009) to share their feelings, attitudes 
as well as thoughts regarding the impending implementation of the ODL. The profiles of these participants are shown in Table 2.

Table 2: Study participants profile

\begin{tabular}{|l|l|l|l|l|}
\hline Participant & Code & Gender & Qualification & Teaching experience \\
\hline 1 & P1 & M & PhD & $>10$ \\
\hline 2 & P2 & M & PhD & $>10$ \\
\hline 3 & P3 & F & PhD & $>10$ \\
\hline 4 & P4 & F & MSc & $<10$ \\
\hline 5 & P5 & M & PhD & $>10$ \\
\hline 6 & P6 & M & Bed & $<10$ \\
\hline 7 & P7 & M & MSc & $<10$ \\
\hline
\end{tabular}

Since we were interested in the views of the faculty members, our sample was not limited to those members that hold key positions within the faculty. We also ensured that other members who do not hold any position also took part to ensure that the sample is representative so long they have taken part in the various workshops related to ODL. Hence, the views provided by the participants could not only be valuable but also representative of the faculty concerning the state of ODL. By sharing their feelings, thoughts, and perceptions about the ODL, we were able to understand the concerns of faculty members regarding ODL.

\section{Data Sources}

We used semi-structured to allow participants to freely articulate their understanding and concerns regarding ODL. Interview items aligned to the seven SoC, described in Table 1, were used to interrogate participants' attitudes, feelings, perceptions regarding ODL implementation. Participants, for instance, participants were asked to articulate and explain their concerns and their perceptions about the impending implementation of ODL.

\section{Data Analysis}

Recorded audio interviews were transcribed verbatim for analysis. Using deductive and inductive analysis approaches (Creswell, 2012), we first familiarized ourselves with the analytical 
framework (stages of concerns). To ensure the dependability of the findings, we all coded the first interview transcript separately using the framework then compared our codes assigned to the transcript and there was a 90\% agreement. We then assigned the first author to code the remaining transcripts. We were interested in the evidence from the participant's talk that aligned with the SoC.

\section{FINDINGS}

\section{Faculty's Concerns Regarding the Implementation of ODL}

Interview data suggests that there are several concerns the faculty have towards the implementation of ODL. These concerns are awareness, information, management, consequences and refocusing.

\section{Awareness Concern Stage}

All participants seem to be aware of ODL. They explained their understanding and gave some examples of the same. For instance, P7 expressed that ODL means "learning by distance". Some even expressed the subtle differences between the two keywords in the phrase "open" and "distance learning." For example, while explaining her understanding of the term ODL, P3 took time to unpack the phrase as follows she first highlighted that ODL currently relies on online platforms as she expresses below:

Online learning it could be teaching and learning using different online platforms... distance learning, can be a blend: online as well as face to face, it can be Aaa using print, so people come and maybe you teach them for some time, you go visit them, use print materials...

Furthermore, participants were able to explain how ODL platforms are used. For instance, P2 explained that he uses ODL platforms to 'compliment' the face to face instruction with his University Certificate of Education (UCE) students. Moreover, participants were able to highlight the importance of ODL platforms. In this regard, P4 stated that "ODL could be critical in the context of COVID-19 such that lectures can be delivered anywhere without physical contact and again even if a lecturer is busy, delivery could be undertaken with no need to cover some distance". P4 was however cautious that not all programs are tenable to ODL as such blended mode of delivery could be explored in such instances. 
The above sentiments indicate that these participants are not only aware of the ODL, but are also aware of the affordances ODL accords the users in the context of covid-19, the teaching and learning process is not affected as there is no reliance on a face to face instruction while using ODL platforms.

\section{Informational Concern Stage}

While participants expressed awareness regarding ODL, they were worried about the way information surrounding ODL is shared at the institution. For instance, P1 says "we don't have enough information". The reason for this, he thinks, is because "...information is more relevant when it is provided at the appropriate time...". However, this raises the issue of when will this appropriate time come. Similarly, P3 and P6 expressed that the lack of information concerning the state of the implementation is worrying as at the time of data collection there had been no arrangements in the school of education that required members of staff to start preparing for teaching using ODL platforms. This is despite the plans to put some of the materials on the ODL platforms. In the same vein, P4 expressed her lack of adequate information regarding ODL at the institution. She reported the following:

I don't have much information. I am more of a technical person focusing more on technical issues surrounding ODL. So, I am only concerned with connectivity issues and ICT tools that could support teaching and learning but I am not aware of the institutional program of implementation.

Hence, to some extent, staff awareness of the ODL efforts has been hampered by a lack of information concerning the implementation of the ODL initiatives.

\section{Management Concern Stage}

Participants expressed their worry about how colleges' management hinders the implementation of the projects. P3 claimed that ODL has not been implemented since “...there hasn't been a willingness on the part of management to make this happen..." This, he believes is further affected by the fact that people believe that "...we have enough already troubling us to think about other things...". While they believe that the university management hampers the implementation of 
ODL, they are of the view that on the other hand management has tried to provide some of the basics such as the internet, training on Moodle etc. which they believe is a node in the positive direction.

On the other hand, P4, as well as P7, had other ideas regarding management commitment to ODL. They expressed that management is supportive of ODL as there are is a variety of ICT tools in place such as Moodle, google classroom, as well as the provision of laptops to every member of faculty involved in teaching. For instance, P4 stated that the college has facilitated training for members of staff in this regard. To her, the environment is supportive however it is the academics themselves that are hampering ODL implementation because in some cases a review of programs is needed to be aligned with ODL and this is a responsibility of deans.

Because of the foregoing, it is clear that management has put the required conditions in place to catalyse ODL's take off. Mindset change amongst academics therefore could be crucial towards the implementation of ODL at the institution.

\section{Consequences Concern Stage}

ODL, according to the participants, has many affordances that need to be fully explored and utilized. For instance, the "uninterrupted calendar" (P5) as well as "enhanced access" (P6) to education are some of the many affordances of ODL that should drive the need to implement it. They observed that the current impact of COVID-19 on the disruption of teaching and learning could be lessened if ODL was implemented and asynchronous learning took place. For instance, one of the participants, when asked if it was right for the school to implement ODL initiatives, said:

We are late - things are supposed to be like that because even for our students (undergraduate), we can make use of what we have... here at our institution, the administration is trying; we have the whole ICT department which is available and then we have laptops we have internet, of course, there are challenges but there is an initiative in that regard [P3]. 
The participant believed that despite a few management issues, an enabling environment has been created to launch ODL initiatives. Furthermore, participants believe that ODL is advantageous in as far as communication with the students is concerned. For instance, P2 claimed that:

It's advantageous and it has been on my part because I can share resources easily, I can make announcements easily, I can even use it to send messages through emails, I can grade assignments through the same interface so it's very advantageous [P2]

\section{Refocussing Concern Stage}

P3, who had been using the Google classroom platform for some time, expressed that one of the ways to make the platform more visible and useable is to have a discussion board where learners could be able to discuss issues that the course lecturer has presented:

I think maybe issues of discussion boards-where-I mean that's an area that I have not tapped into, but I think if there could be that facility where you can have students have discussions easily aaa you pose a question and then they answer then that kind of thing [P3]

The above presents evidence for the concerns regarding ODL implementation faculty members has at this institution.

\section{FACULTY PERCEPTIONS OF THE SCHOOL OF EDUCATION'S PREPAREDNESS TO IMPLEMENT ODL}

At the time of data collection, while participants expressed that COVID-19 has presented the school an opportunity to accelerate the implementation of ODL initiatives, they however expressed reservations that the school was not ready to implement ODL initiatives as summarised in table 3 . This represents some sort of mixed feeling. This was attributed to several factors including the willingness of the administration to give a clear direction on the implementation of the ODL initiatives. This is worrisome especially considering that some participants expressed that the same administration has put in every effort to roll out the ODL. 
Table 3: Showing issues raised by participants concerning faculty preparedness

\begin{tabular}{|l|l|}
\hline Faculty preparedness & Examples \\
\hline Minimal preparation & no content \\
no progress concerning content development
\end{tabular}

When asked to express their ideas concerning the school's preparedness to implement ODL, while acknowledging that the COVID-19 might have presented the school of education an opportunity to accelerate the implementation of ODL initiatives, participants' responses were negative. Some of the reasons that came out strongly were: members of faculty orientation towards ODL, lack of policy awareness, issues related to the management and administration, issues related to copyrights of the content developed by the staff members, and lack of preparation on the part of staff members and students. 


\section{Minimal Preparation}

Participants were of the view that ODL was far from being implemented since most of the staff is yet to adapt their course content into units for online platforms such as Moodle. One participant challenged that:

Suppose today someone offered all students laptops, and free internet data can we start online lessons? My simple answer is No we cannot. Which to me suggest that we are trying to deal with a level 2 problem skipping level 1[P2]

Similarly, P3 agreed with the above sentiments that staff members first needed to adapt their course content into materials suitable for online learning. She claimed that "we have the materials but to put them in a form where somebody can use and understand effectively at a distance requires adjustment...distance materials should be self-sufficient so that they can easily be understood." These sentiments suggest that most members use the lack of other basics as an excuse for their unpreparedness. He, therefore, challenged the members that rather than worrying about how students would access the content or how issues of assessment would be addressed, the big issue should be about how much content of the courses that the members are teaching currently has been adapted for online learning.

\section{Members of faculty orientations towards $O D L$}

Faculty orientation is also another hindrance that has led to the faculty not implementing ODL initiatives. Participants believe that one's orientations about ODL (persons will, attitude towards $O D L$, the practicality of $O D L$ for science courses, one's attitude towards on status quo) can be an enabler or a hindrance in the implementation process. Those with negative orientations will be unwilling to take part in the implementation process unlike those with positive orientations. For instance, one participant who once served as a director of e-learning argued that most staff members seem to be contented that the only way of offering their courses and producing graduates is through face to face interaction. While this is true to some extend, he argued that knowledge is tentative, environments also change. This means that people must be willing to change the way they conduct their activities. He challenged that this inability to move with time and their limited conceptualization that teaching and learning only emanates from face to face interaction is, 
therefore, a grave mistake. He cited several examples of institutions that have successfully produced graduates using online learning platforms. Below is an extract of his observation:

This is a grave misconception, the fact that we have spent the most time in face-to-face learning activities should not imply that this is the only set of activities that produce learning. History is replete with many people who made it but not through face-to-face, else we should not have universities like Open University in the UK [P2].

P4 on the other hand provided evidence that the lack of implementation is largely a result of the negative orientations people have towards ODL when she said:

ODL resources are available but are not fully utilized. Mindset change is needed for us to actualize ODL. As I highlighted earlier we have a technical foundation in place to support ODL however programs are owned by the deans and we don't have control. Let deans review their programs so that they be in sync with ODL as they were initially approved as face to face. As technical people, we have done our part

The above sentiments are an indication that the lack of implementation of ODL at the institution should be linked to a lack of infrastructure or technical expertise since these are readily available to provide support. What is lacking, therefore, is the willingness to actualise the ODL programmes. The implication of this, therefore, is that there is a need for staff re-orientation towards ODL. One way of ensuring positive orientations for both staff and students, she suggests, is to "embark on sensitization campaigns among academics and students as mindset change is a crucial element in the effective implementation of ODL".

Apart from that, she further proposed that technical support could be provided in terms of bandwidth and cheaper data bundles to ensure that these barriers are no longer presented as an excuse. Furthermore, she also highlighted the need to review most of the programmes to be in tandem with ODL. 


\section{Lack of Policy Awareness and Copyright Issues}

Some participants also noted that ODL implementation initiatives were affected by the little policy awareness as well as the unresolved copyright issues. P1 claimed that, at the training workshop on content development for online learning, copyright issues were raised by the members. Questions such as "how will content developers benefit from such efforts?" were unresolved as P1 recalled:

There has been some effort to upload material by the college so that we could offer some sort of online education. That has not yet materialized I think because of issues of copyright. Staff members raised questions of copyright which were not addressed. So, there hasn't been a move ahead.

The lack of resolve to address the member's concerns appear to have discouraged most members to work towards transforming their course content into units that could be uploaded onto online platforms.

\section{DISCUSSION AND CONCLUSION}

In this study, we explored the concerns of faculty members regarding ODL using the ConcernsBased Adoption Model. The study has revealed that the CBAM is a fruitful model for exploring the concerns of the participants even before the innovation has been implemented. The study has specifically unearthed faculty concerns that might be useful for designing various support structures and planning for rolling out ODL.

This was one of the few studies that sought to qualitatively explore the faculty concerns on the implementations of ODL at a public university in Malawi. Consistent with previous research (Barker, 2003; Appana,2008) and viewed through the lens of the CBAM (Anderson, 1997), data indicated that faculty had four concerns on the implementation of ODL: awareness, information, refocusing and consequences. This may not be surprising because participants have been musing about the innovations based on the various workshops that have been organized towards the implementation of ODL. Despite these concerns, we noted subtle differences in the concerns expressed by the participants based on their backgrounds. For instance, concerning the level of preparedness, we noted that while other participants commended the administration for doing something towards the implementation of ODL, others perceived the same administration as a 
hindrance. These differences are also supported in the literature (for instance, George et al., 2013). George et al. (2013) claim that as different people are attached differently to various innovations, they are bound to express their concerns differently.

The above-identified concerns reveal the teacher educators professional knowledge (pedagogy of teacher education, producing and consuming research, community service and understanding of policy (Goodwin \& Kosnik, 2013) gaps. Research shows that these knowledge domains are critical if teacher educators are to effectively discharge their duties (Goodwin \& Kosnik, 2013). Along these, we propose robust Professional Development (PD) programmes that would help in addressing these gaps. During our interaction with the participants, we noted that in most of the PD workshops the participants took part in, the focus was on participants' awareness of the ODL initiatives. Our study, however, uncovered some other potential areas of focus during such PD workshops. These areas include; efforts geared toward discussing members orientations towards ODL would be ideal in changing faculty members orientations towards ODL. Hence deliberate PD activities that are aimed at raising awareness, targeting reorienting faculty members attitudes towards ODL as well as making members more knowledgeable in issues related to the use of technology during instruction could be ideal towards ensuring that members embrace the use of technology in education.

In the literature review section, we discussed the various professional knowledge domains that are critical for teacher educators. Along the same lines, we also propose that knowledge about technology and education be viewed as one of the important knowledge domains teacher educators ought to have. This is especially true in the context of COVID-19 where teacher educators need to be well versed in issues related to the affordances of technology as ways of not only mitigating the impacts of pandemics such as covid-19 but also as a tool towards enhancing access to higher education institutions. We share the belief that a good grasp of issues surrounding the use o technology in education would ensure that members are not caught off guard when another pandemic hits, it would also ensure that members have a positive orientation towards the use of technology for every subject discipline. Along these lines, teacher education programmes should also be able to discuss current issues that have the potential of disrupting teaching and learning just like the COVID-19 pandemic. 
We have also highlighted that despite the concerns raised, the faculty held a positive attitude toward the potential of ODL at the institution. Yet, given their concerns, the challenge is to translate the faculty positivity into the actual implementation of ODL. On one hand, the factors reported in previous studies (Kadzera, 2006; Nyirongo, 2009) offer the potential to understand that faculty development is one of the action points to improve faculty use of modern technology for ODL purposes in Malawi's higher education institutions. On the other hand, the present study suggests that the transition might require more than staff development. Apart from faculty knowledge and skills, the faculty concerns reported in this study are to do with their attitudes. The data and focus of this paper do not permit us to draw conclusions that might be useful for addressing faculty concerns. However, the findings underscore the mounting proper professional development programmes that would properly re-orient members to have a positive attitude towards ODL. For practice, the findings have offered the opportunity to understand the prevailing concerns which might be considered at the institutional, policy and programme level of technology professional development for teacher educators at the institution under study.

Among others, this case study offers insights for designing professional development programmes aimed at preparing teacher educators in the use of modern technology for ODL. Moreover, we envisage that findings from this study will add value to the successful implementation of ODL interventions currently being conceptualized in Malawi and elsewhere as education institutions grapple with other emergencies beyond the current COVID-19 pandemic.

\section{AUTHOR CONTRIBUTION}

Bob Maseko: Development of the research concept, data collection, data analysis and overall write up of the manuscript.

Foster Gondwe: Development of the research concept, literature review, data analysis, and write up.

Symon Winiko: Development of the research concept, data collection, data analysis and manuscript write up.

Symon Chiziwa: Development of the research concept and write up. 


\section{REFERENCES}

Anderson, S. E. (1997). Understanding Teacher Change: Revisting the Concerns Based Adoption Model. Curriculum Inquiry, 27(3), 38.

Barker, A. (2003). Faculty Development for Teaching Online: Educational and Technological Issues. The Journal of Continuing Education in Nursing, 34(6), 273-278. https://doi.org/10.3928/0022-0124-20031101-10

Bourn, D. (2016). Teachers as agents of social change. International Journal of Development Education and Global Learning, 7(3), 63-77. https://doi.org/10.18546/IJDEGL.07.3.05

Commonwealth of Learning. (2002). Distance education and open learning in Sub-Saharan Africa - A literature survey on policy and practice. The Commonwealth of Learning, 153.

Creswell, J. W. (2012). Educational research: Planning, conducting, and evaluating quantitative and qualitative research (4th ed). Pearson.

Ferdig, R. E., \& Pytash, K. E. (2021). What Teacher Educators Should Have Learned From 2020 (pp. 1-264). Association for the Advancement of Computing in Education (AACE). https://www.learntechlib.org/primary/p/219088/

George, A. A., Hall, G. E., \& Stiegelbauer, S. M. (2013). Measuring implementation in schools: The stages of concern questionnaire. Southwest Educational Development Laboratory.

Goodwin, A. L., \& Kosnik, C. (2013). Quality teacher educators = quality teachers? Conceptualizing essential domains of knowledge for those who teach teachers. Teacher Development, 17(3), 334-346. https://doi.org/10.1080/13664530.2013.813766

Greenberg, G. (1998). Distance education technologies: Best practices for K-12 settings. IEEE Technology and Society Magazine, 17(4), 36-40. https://doi.org/10.1109/44.735862

Hall, G. E., \& Hord, S. M. (2015). Implementing Change: Patterns, Principles, and Potholes (4th ed.). Pearson.

Hancock, D. R. (2006). Doing Case Study Research: A Practical Guide for Beginning Researchers. 122. 
Kadzera, C. M. (2006). Use of Instructional Technologies in Teacher Training Colleges in Malawi. Virginia Polytechnic Institute and State University.

Kang, J. H., \& Everhart, N. (2014). Digital textbooks: School librarians'stages of concerns in initial implementation. 23.

Lunenberg, M., Dengerink, J., \& Korthagen, F. (2014). The Professional Teacher Educator: Roles, Behaviour, and Professional Development of Teacher Educators. SensePublishers. https://doi.org/10.1007/978-94-6209-518-2

Merriam, S. B., \& Merriam, S. B. (2009). Qualitative research: A guide to design and implementation. Jossey-Bass.

Mkandawire, G. B., \& Kaphesi, E. (2017). Students' perceptions of the open and distance learning mode for initial primary teacher training in Malawi: A case of Lilongwe Teachers' College. Journal of Research in Open, Distance and eLearning, 1(1), 1-19. https://doi.org/10.26841/2017e05

Mkandawire, M. (2020, April). Airtel, TNM facilitate e-learning for students in Malawi [Https://malawi24.com/2020/04/21/airtel-tnm-facilitate-e-learning-for-students-inmalawi/]. Malawi24. https://malawi24.com/2020/04/21/airtel-tnm-facilitate-e-learningfor-students-in-malawi/

Moore, J. L., Dickson-Deane, C., \& Galyen, K. (2011). e-Learning, online learning, and distance learning environments: Are they the same? The Internet and Higher Education, 14(2), 129135. https://doi.org/10.1016/j.iheduc.2010.10.001

Mtingwi, J., \& Belle, J.-P. V. (2012). The State of E-Government and M-Government Readiness in Malawi. International Journal of Information Technology, 6, 11.

Mutton, T. (2020). Teacher education and Covid-19: Responses and opportunities for new pedagogical initiatives. Journal of Education for Teaching, 46(4), 439-441. https://doi.org/10.1080/02607476.2020.1805189 
Nyirongo, N. K. (2009). Technology adoption and integration: A descriptive study of a higher education institution in a developing nation. Virginia Polytechnic Institute and State University.

Ping, C., Schellings, G., \& Beijaard, D. (2018). Teacher educators' professional learning: A literature review. Teaching and Teacher Education, 75, 93-104. https://doi.org/10.1016/j.tate.2018.06.003

Smidt, E., Bunk, J., McGrory, B., Li, R., \& Gatenby, T. (2014). Student Attitudes about Distance Education: Focusing on Context and Effective Practices. IAFOR Journal of Education, 2(1). https://doi.org/10.22492/ije.2.1.02

Teaster, P. B., \& Blieszner, R. (1999). Promises and Pitfalls of the Interactive Television Approach to Teaching Adult Development and Aging. Educational Gerontology, 25(8), 741-753. https://doi.org/10.1080/036012799267477

Tembo, K. A. (2019). Expanding Access to Higher Education in Public Universities through Open and Distance Learning (ODL) in Malawi: Quality Issues. 1(3), 10.

Trapani, B. (2019). Crossing the Bridge of Change: Measuring Instructional Change Using the Concerns Based Adoption Model. 5.

Zozie, P., \& Chawinga, W. D. (2018). Mapping an open digital university in Malawi: Implications for Africa. Research in Comparative and International Education, 13(1), 211-226. https://doi.org/10.1177/1745499918761952 